\title{
Effects of Adding Intrathecal Dexmedetomidine to Hyperbaric Bupivacaine for Saddle Spinal Block in Adults Undergoing Peri-anal Surgeries
}

\author{
Binod Gautam, ${ }^{1}$ Sushila Moktan Lama, ${ }^{1}$ Mona Sharma ${ }^{1}$ \\ ${ }^{1}$ Department of Anesthesia and Intensive Care, Kathmandu Medical College Teaching Hospital, Kathmandu, \\ Nepal.
}

\section{ABSTRACT}

\begin{abstract}
Background: Saddle spinal block is the first choice anesthetic technique for adults undergoing peri-anal surgeries. It prevents unnecessary high levels of analgesia and sympathetic block. However, it may not provide prolonged analgesia. This study aims to investigate analgesic effects of dexmedetomidine when added to hyperbaric bupivacaine in saddle spinal block.

Methods: Fifty otherwise healthy adults scheduled for uncomplicated peri-anal surgery were randomly allocated into two equal groups in this double-blinded study. Group A received hyperbaric bupivacaine five milligrams; group B received hyperbaric bupivacaine five milligrams plus dexmedetomidine five micrograms intrathecally. Patients remained seated for ten minutes. Time to first analgesic request by patients was the primary end point. Onset and extent of sensory block, and, magnitude and duration of motor block were assessed. Post-operative analgesic consumption and side effects were studied for 24 hours. Student's t-test for quantitative variables and Chi-square test for categorical variables were used for statistical analysis.

Results: Patients in group B had a significantly prolonged duration of analgesia (group B, $501 \pm 306$ minutes; group A, $284 \pm 58$ minutes) and significantly reduced analgesic requirement than patients in group A. Sensory block in first sacral dermatome appeared significantly earlier in group B. Peak sensory block, magnitude of motor block, and side effects were not significantly different between groups A and B.

Conclusions: Dexmedetomidine as an intrathecal adjuvant to hyperbaric bupivacaine in saddle spinal block prolongs duration of analgesia and decreases analgesic requirement with no added side effects.

Keywords: Bupivacaine; dexmedetomidine; intrathecal adjuvant; saddle spinal block.
\end{abstract}

\section{INTRODUCTION}

Saddle Spinal Block (SSB) is the most common anesthetic technique employed for peri-anal surgeries in adults. By injecting low dose hyperbaric local anesthetic intrathecally in seated patients, it limits sympathetic block and allows earlier ambulation. ${ }^{1}$ However, it doesn't offer prolonged analgesia, especially when sole local anesthetic is used. ${ }^{2}$

Various intrathecal adjuvants are used to improve quality and duration of analgesia. Intrathecal opioids prolong analgesia, but side effects limit their routine use.3,4 Dexmedetomidine, a selective alpha-2 adrenoceptor agonist, has been used intrathecally for its antinociceptive properties. ${ }^{5 \cdot 7}$ But clinical studies evaluating its application in SSB are very sparingly available.
This study primarily aims to test hypothesis that dexmedetomidine five micrograms $(\mathrm{mcg})$ used as intrathecal adjuvant to hyperbaric bupivacaine five milligrams $(\mathrm{mg})$ in SSB prolongs analgesia following uncomplicated peri-anal surgery in adults. The secondary objectives included block characteristics and side effects.

\section{METHODS}

This is a randomized, double-blinded, parallel-arm interventional study done at operating room and postoperative recovery area from February 15, 2017 to November 15, 2017. Ethical approval was obtained from Institutional Review Committee before its start. Informed written consent from each participant was 
obtained during pre-anesthetic evaluation.

In a previous study, duration of analgesia was normally distributed with standard deviation of $101 .{ }^{8}$ For clinically important difference taken at 90 minutes, 20 subjects are needed in each group. Adjusting calculations for block failure and loss to follow up of $25 \%$ gives sample size for each group to be 25 .

Random allocation sequence was generated by principal investigator using Microsoft Office Excel 2007. It was concealed in sequentially numbered sealed opaque envelops that were opened at time of intervention.

American Society of Anesthesiologists' physical status one and two patients, from both gender, of 18 to 65 years age who were scheduled to surgery for their uncomplicated hemorrhoids or anal fistula in lithotomy position were included. Patients with following conditions were excluded: pregnancy, infection focus at back, history of spine surgery, heart block, cardiac conduction defects, arrhythmias, coagulopathy, mental disturbance, neurological disease, hypersensitivity to local anesthetics or dexmedetomidine, intake of experimental or analgesic medication within last 24 hours and patients receiving alpha-adrenergic antagonist, calcium channel blocker, angiotensin converting enzyme inhibitor/blocker, beta-blocker, anti-arrhythmic or anticoagulant.

Patients were fasted for six hours prior to surgery and no sedative, analgesic or anti-emetic was prescribed as premedication. In operating room baseline systolic blood pressure (SBP), heart rate (HR) and respiratory rate (RR) were recorded. Routine monitors (non-invasive blood pressure, pulse-oximetry and electrocardiography) were established. Intravenous line was secured with 18 $\mathrm{G}$ cannula to start Ringer's Lactate infusion which was restricted at five to seven $\mathrm{ml} / \mathrm{kg} / \mathrm{hr}$ peri-operatively.

Dural puncture was performed in sitting patient following aseptic precautions with $27 \mathrm{G}$ pencil-point spinal needle at L3/L4 intervertebral space through midline approach. Patients were randomized into two groups $A$ and B of 25 each. Test drug solution was prepared by an investigator not involved in assessment of study outcomes. Participants, anesthesia administrator and outcome assessors were blinded to the group allocation. Group A received one milliliters $(\mathrm{ml})$ hyperbaric bupivacaine $0.5 \%$ (Bupican $^{T M}$ Heavy: Claris Injectables Ltd, Ahmedabad, India) and $0.5 \mathrm{ml}$ normal saline. Group $B$ received one $\mathrm{ml}$ hyperbaric bupivacaine $0.5 \%$ and five mcg dexmedetomidine (Xamdex ${ }^{\mathrm{TM}}$ : Dexmedetomidine $100 \mathrm{mcg} / \mathrm{ml}$; Themis Medicare Ltd, Uttarakhand, India) freshly prepared in $0.5 \mathrm{ml}$ normal saline $(100 \mathrm{mcg}$ in $10 \mathrm{ml}$ ). After aspiration, bupivacaine was injected intrathecally over two minutes (min). This was followed by test drug injection over 15 seconds using a separate syringe. Spillage of initially administered drug was avoided by gently raising the spinal needle hub before changing the syringe containing test drug. Time of completion of injection was used as the primary starting point of assessment. With an assistant's support patients remained seated for another ten minutes.

Level of sensory block was assessed using spirited cotton swab for cold sensation. Time to first sacral dermatome (S 1) sensory block, defined as loss of sensation over bilateral little toes was recorded, and when surgical proceedings were permitted. Sensory assessment continued every two minute till attaining peak sensory block, defined as the same highest level recorded on three consecutive readings. Motor block of lower limbs was assessed according to modified Bromage Scale (Appendix 1). ${ }^{9}$ Maximum motor block was defined as Bromage scale attained at time of peak sensory block and duration of motor block was determined by hourly assessment till its regression to Bromage 0 .

$\mathrm{HR}, \mathrm{SBP}$ and RR were monitored every five minutes intraoperatively, every 15 min for two hours, hourly for next three hours and two hourly there after. Hypotension (more than 20\% fall in SBP from baseline) was treated with ephedrine. Bradycardia ( $\mathrm{HR}<50$ beats/min) was treated with Atropine. Respiratory depression (RR<eight breaths/min) was treated with oxygen supplementation and respiratory support as needed. Sedation level was assessed at 15, 30, and 60 minutes using Ramsay Sedation Score (Appendix 2). ${ }^{10}$ Occurrence of nausea, vomiting, and shivering were recorded. Amounts of fluid infused, blood loss, and need for sedative, analgesic, anti-emetic and any other medication were recorded.

Patients and caring nurses in post-operative recovery area were instructed to notify the investigator whenever patient sensed pain in surgical site. Duration of analgesia, the primary end point of study, was calculated from time of completion of intervention to the time of first analgesic request by patient, when Verbal Analogue Score (VAS) for pain exceeded three out of ten. Analgesics were administered on surgeons' discretion. Frequency of analgesics administered, time to first selfvoid and urinary retention requiring catheterization as per surgeons' judgment were recorded from nursing chart at $24^{\text {th }}$ hour when study period ended.

For analysis, statistical package for social science evaluation version 20 (SPSS Inc; Chicago, IL) was used. 
Data were expressed as mean, standard deviation and standard error of mean or numbers. Student's t-test was performed to compare continuous variables. Chi-square test was used for nominal variables. Ordinal variables were analyzed using Mann-Whitney U-test. The level of significance used was $p<0.05$.

\section{RESULTS}

Saddle spinal block was possible in all participants and there was no need for rescue analgesic or general anesthesia during surgery. The spillage of the initially administered drug was not observed in any participant while changing the syringe for injecting the study drug. Two participants in group $B$ decided to leave hospital on the same day without reaching the primary end point of study. Analysis included 25 patients in group A and 23 patients in group $B($ Figure 1).

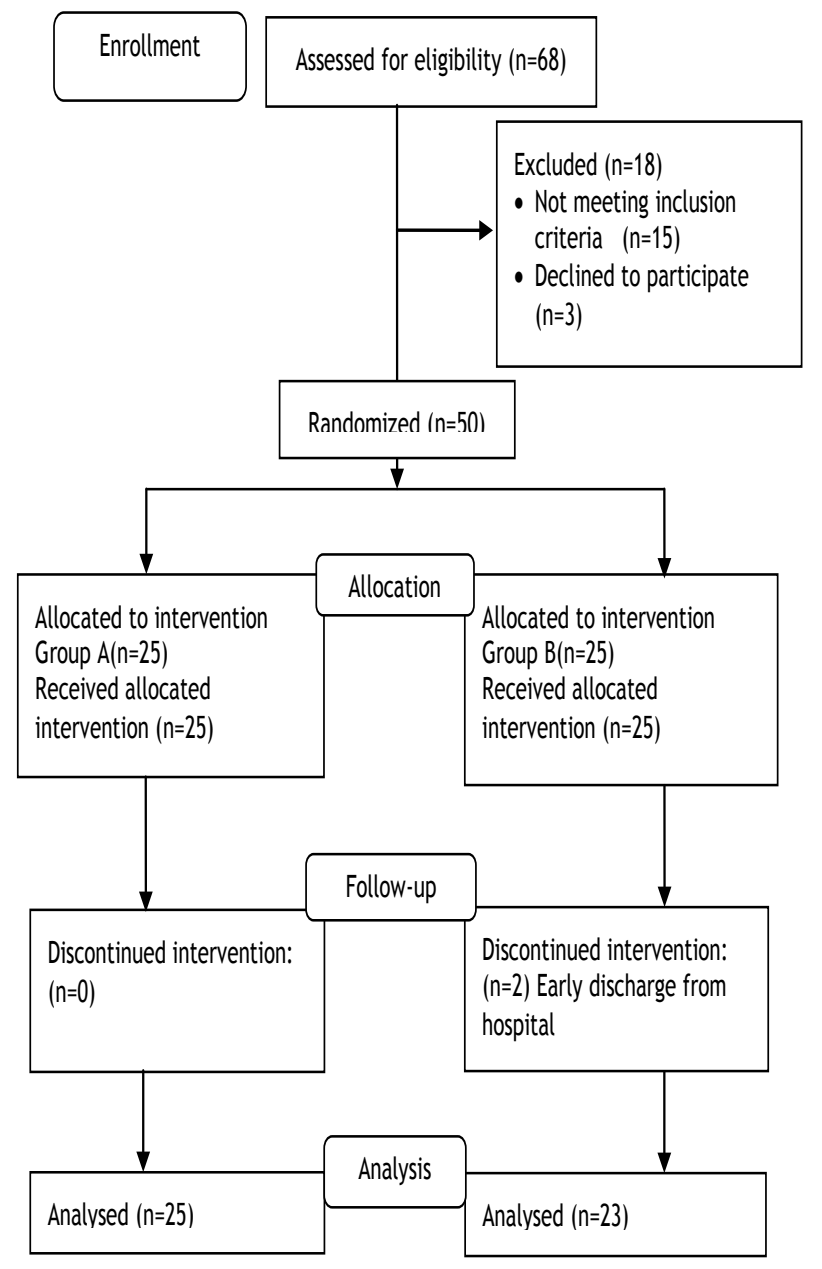

Figure 1. Flowchart of the study.

Demographic profile and operative characteristics were similar between groups (Table 1 ).
Table 1. Demographic profile and intra-operative characteristics.

\begin{tabular}{|c|c|c|c|}
\hline Characteristics & $\begin{array}{r}\text { Group A } \\
(n=25)\end{array}$ & $\begin{array}{r}\text { Group B } \\
(n=23)\end{array}$ & $\begin{array}{r}p \\
\text { value }\end{array}$ \\
\hline \multirow[t]{2}{*}{ Age (years)* } & $45.96(14.86)$ & $51.0(9.86)$ & 0.176 \\
\hline & 2.97 & 2.04 & \\
\hline $\begin{array}{l}\text { Gender }^{\dagger} \\
\text { (Male:Female) }\end{array}$ & $16: 9$ & $9: 14$ & 0.148 \\
\hline \multirow[t]{2}{*}{ Weight (kilograms) ${ }^{*}$} & $54.84(11.04)$ & $59.22(9.64)$ & 0.152 \\
\hline & 2.20 & 2.01 & \\
\hline \multirow{2}{*}{$\begin{array}{l}\text { Height } \\
\text { (centimeters)* }\end{array}$} & $157(5.48)$ & $158.48(6.56)$ & 0.400 \\
\hline & 1.09 & 1.36 & \\
\hline
\end{tabular}

\begin{tabular}{|c|c|}
\hline $\begin{array}{l}\text { Surgery }{ }^{\dagger} \text { (Hemor- } \\
\text { rhoidectomy: }\end{array}$ & $15: 10$ \\
\hline
\end{tabular}

Fistulectomy)

$\begin{array}{lrrr}\begin{array}{l}\text { Duration of surgery } \\ \text { (minutes) }^{*}\end{array} & 26.52(9.62) & 27.6(12.09) & 0.731 \\ & 1.92 & 2.52 & \end{array}$

$\begin{array}{lrrr}\text { Total intravenous } & 336(102.59) & 330(96.22) & 0.847 \\ \text { fluid (milliliters) } & 20.51 & 20.06 & \\ & & & \\ & & & \\ & & & \\ \begin{array}{l}\text { Intraoperative } \\ \text { blood loss (ml)* }\end{array} & 8.80(4.15) & 12.61(13.04) & 0.172 \\ & 0.831 & 2.72 & \end{array}$

* mean(standard deviation) standard error of mean, ${ }^{\dagger}$ number

Time to reach S-1 sensory block was significantly early in group $\mathrm{B}($ Table 2$)$. Other block characteristics are shown in Table 2.

Bradycardia, hypotension and respiratory depression were not witnessed throughout study period. Intraoperatively, sedatives were demanded in five and two patients in groups $A$ and $B$ respectively $(p=0.419)$. Ramsay Sedation Scores, however, did not exceed two (median 2) in both groups at any time intervals studied. Shivering occurred in four and two patients in groups $A$ and $B$ respectively $(p=0.668)$.

Duration of analgesia was significantly prolonged and analgesic consumption was significantly reduced in group B (Table 3). 


\begin{tabular}{|c|c|c|c|}
\hline $\begin{array}{l}\text { Block } \\
\text { characteristics }\end{array}$ & $\begin{array}{r}\text { Group } \\
A(n=25)\end{array}$ & $\begin{array}{c}\text { Group B } \\
(n=23)\end{array}$ & $\begin{array}{r}p \\
\text { value }\end{array}$ \\
\hline $\begin{array}{l}\text { Time to } S-1 \\
(\min )^{*}\end{array}$ & $\begin{array}{r}6.24(2.08) \\
0.417\end{array}$ & $\begin{array}{r}4.61(1.75) \\
0.365\end{array}$ & 0.005 \\
\hline $\begin{array}{l}\text { Time to peak } \\
\text { sensory block } \\
(\min )^{*}\end{array}$ & $\begin{array}{r}14.08(3.36) \\
0.686\end{array}$ & $\begin{array}{r}15.55(5.29) \\
1.184\end{array}$ & 0.271 \\
\hline $\begin{array}{l}\text { Peak sensory } \\
\text { block }^{\dagger}\end{array}$ & $\begin{array}{r}\text { L3 (L5 to } \\
\text { T11) }\end{array}$ & L2 (L5 to T10) & $0.101^{\ddagger}$ \\
\hline $\begin{array}{l}\text { No. of derma- } \\
\text { tomes blocked }\end{array}$ & 7 (5 to 11$)$ & 8 (5 to 12$)$ & \\
\hline \multicolumn{4}{|l|}{$\begin{array}{l}\text { Maximum motor } \\
\text { block: }\end{array}$} \\
\hline $\begin{array}{l}\text { BromageScale } \\
0 / 1 / 2 / 3\end{array}$ & $20 / 4 / 1 / 0$ & $16 / 5 / 2 / 0$ & 0390 ₹ \\
\hline Median (range) & $0(0$ to 2$)$ & $0(0$ to 2$)$ & $0.390^{+}$ \\
\hline $\begin{array}{l}\text { Duration of } \\
\text { motor block } \\
(\min )^{*}\end{array}$ & $\begin{array}{r}144.0(32.86) \\
14.697\end{array}$ & $\begin{array}{r}187.50(55.67) \\
21.023\end{array}$ & $0.166^{\prime \prime}$ \\
\hline
\end{tabular}

${ }^{*}$ mean (standard deviation)standard error of mean, ${ }^{\dagger}$ median (range), "Mann-Whitney U-test, ${ }^{\S}$ number, "analyzed only for cases showing motor block

\section{Table 3. Post-operative pain and analgesia characteristics. Group A (n=25) Group B $(n=23) \quad p$}

Duration of $284.24(58.38) \quad 501.35$ (306.46) $\quad 0.001$ analgesia

$$
11.67 \quad 63.90
$$

$(\min )^{*}$

Frequency
of
analgesics

analgesics ${ }^{\dagger}$

$\begin{array}{llll}\begin{array}{l}\text { VAS at first } \\ \text { analgesic } \\ \text { request }\end{array} & 5(4 \text { to } 9) & 5(4 \text { to } 8) & 0.326 \\ \begin{array}{l}\text { VAS at } 24 \\ \text { hours }^{\dagger}\end{array} & 3(0 \text { to } 4) & 3(0 \text { to } 6) & 0.991\end{array}$

" mean (standard deviation)standard error of mean, ${ }^{\top}$ median (range) and Mann-Whitney U-test applied, VAS = Pain (Verbal Analogue Score) score.

Post-operatively, anti-emetic was administered in three group A patients for nausea $(p=0.235)$. The difference between groups in mean times to first self-void (group A, $331.33 \pm 62.13 \mathrm{~min}$; group $B, 366.60 \pm 77.27 \mathrm{~min}$ ) did not reach statistical significance $(p=0.101)$. Urinary retention was evident in one and two patients in groups $A$ and $B$ respectively $(p=0.601)$. Two patients in group $A$ and one patient in group $B$, respectively, needed treatment for epigastric pain and non-specific headache.

\section{DISCUSSION}

Dexmedetomidine five mcg used as an intrathecal adjuvant to hyperbaric bupivacaine five $\mathrm{mg}$ in SSB was found to significantly prolong duration of analgesia and resulted in a significant reduction in analgesic requirement.

Analgesia prolonging action of dexmedetomidine, a highly selective alpha-2 adrenoceptor agonist, when co-administered with local anesthetic intrathecally is thought to result from its binding to pre-synaptic $\mathrm{C}$-fibers and post-synaptic dorsal horn nucleus in spinal cord. ${ }^{5}$ Either additive or synergistic influence of these agents to the effects of local anesthetics may be related to their lipophilicity. ${ }^{11,12}$

In our study, duration of analgesia was significantly prolonged in dexmedetomidine group, which is in agreement with results from previous studies. ${ }^{6,13,14}$ However, these studies employed larger doses of local anesthetic. Adding dexmedetomidine to smaller dose of bupivacaine has also been shown to significantly prolong analgesia. ${ }^{7}$ Dispersion of data with a greater standard deviation observed in our dexmedetomidine group matches with a meta-analysis where significant heterogeneity amongst participants was evident. ${ }^{15}$ Our finding that couple of patients in dexmedetomidine group requiring no analgesics for 24 hours is seemingly responsible.

Sensory block to $S 1$, minimally required level for peri-anal surgery, appeared early in dexmedetomidine group in our study. There are not much similar studies to compare our results with. Sudheesh et al reported that addition of dexmedetomidine in SSB resulted in $\mathrm{S}$ 1 block at 7.69 minutes; however, they used a slightly lower dose of four mg bupivacaine than that of ours. ${ }^{8}$ Kim JE et al showed faster onset to peak sensory block (eight vs. 10 minutes) when three mcg dexmedetomidine was added to six mg bupivacaine; but their participants were elderly and intrathecal injection was performed in lateral decubitus position. ${ }^{7}$

Frequency of analgesic requirement was significantly reduced by dexmedetomidine in our study. This finding compares with Gupta et al showing 64\% decrement in 24 hours' analgesics consumption by dexmedetomidine. ${ }^{14}$ VAS at time of first analgesic request and $24^{\text {th }}$ hour 
in our study being similar ascertains uniform pain management; even though, it was based on surgeons' judgment, reflecting the usual clinical practice.

Regression of sensory block was not studied, because it was perceived that pain around surgical site and request of analgesic for the same would be clinically more important. Moreover, frequent sensory assessments around private parts could prove harassing for these patients.

Pain around anal region is intense and reflexogenic; and, operations require deep levels of anesthesia. ${ }^{2,16}$ SSB proved to be excellent in that aspect, as well as in avoiding hypotension and bradycardia in our study. The essence of SSB is to target sacral nerve roots with a small bolus drug solution whose intrathecal spread is determined primarily by baricity and influence of gravity. ${ }^{17}$ Spread of low dose spinal anesthetic is reduced by low speed of injection and maintenance of position. ${ }^{18}$ Following the recommendations, speed of injection was two minutes and patients were kept in sitting position for ten minutes in our study. To avoid unknown consequences on its baricity, hyperbaric bupivacaine was not mixed with normal saline. We rather utilized two different syringes for injection, as normal saline was reported to be hypobaric. ${ }^{19}$

Minimal effective dose of bupivacaine for SSB ranges from four to $7.5 \mathrm{mg}$; we used five $\mathrm{mg} .^{1,8,20,21}$ The technique, low dosage, and lipophilic nature of dexmedetomidine might have contributed for the lack of increment in peak sensory block, number of blocked dermatomes and magnitude of motor block. This in turn explains the similarity between groups regarding time to void and urinary retention. Although not studied, these findings might reflect that intrathecal dexmedetomidine poses no adverse impact on ambulation and discharge time.

Because of anti-hypertensive medications intake, advanced age, and prone positioning preferred by surgeons, quite a few number of patients were excluded. Given the increasing prevalence of elderly and hypertensive patients, this represents a substantial limitation, and a further study including these population is warranted.

This technique doesn't demand complex skill and appliances; nor does it require intensive monitoring, for its lack of serious side effects. It would thus benefit this surgical population who in early post-operative period experiences the most intense pain. Also, dosedependent effects of intrathecal dexmedetomidine are consistent at a range of three to $10 \mathrm{mcg} \cdot{ }^{6,8,13,14}$ Future research will be appropriate to clarify dose-related response to dexmedetomidine and its potential to reduce local anesthetic dose requirement amongst appropriate surgical population.

\section{CONCLUSIONS}

We conclude that dexmedetomidine used as an intrathecal adjuvant to hyperbaric bupivacaine in saddle spinal block prolongs analgesia and reduces analgesic consumption, without adding side effects, after elective peri-anal surgery in adults.

\section{REFERENCES}

1. Gudaityte J, Marchertiene I, Karbonskiene A, Saladzinskas Z, Tamelis A, Pavalkis D. Low-dose spinal hyperbaric bupivacaine for adult anorectal surgery: a double-blinded, randomized, controlled study. J Clin Anesth. 2009; 21(7):474-81. [Science Direct] DOI

2. Liu SS. Optimizing spinal anesthesia for ambulatory surgery. Reg Anesth. 1997; 22(6):500-10.

3. Etches RC, Sandler AN, Daley MD. Respiratory depression and spinal opioids. Can J Anaesth. 1989; 36(2):165-85. [Full Text] DOI

4. Chaney MA. Side effects of intrathecal and epidural opioids. Can J Anaesth. 1995; 42(10):891-903.[Full Text] $\underline{\mathrm{DOI}}$

5. Eisenach JC, Shafer SL, Bucklin BA, Jackson C, Kallio A. Pharmacokinetics and pharmacodynamics of intraspinal dexmedetomidine in sheep. Anesthesiology. 1994; 80(6):1349-59. [Full Text]

6. Kanazi GE, Aouad MT, Jabbour-Khoury SI, Al Jazzar MD, Alameddine MM, Al-Yaman R, et al. Effect of low-dose dexmedetomidine or clonidine on the characteristics of bupivacaine spinal block. Acta Anaesthesiol Scand. 2006; 50(2):222-27. [Full Text]

7. Kim JE, Kim NY, Lee HS, Kil HK. Effects of intrathecal dexmedetomidine on low-dose bupivacaine spinal anesthesia in elderly patients undergoing transurethral prostatectomy. Biol Pharm Bull. 2013; 36(6):959-65.[Full Text]DOI

8. Sudhhesh K, Raghavendra Rao RS, Kavya M, Aarthi J, Rani DD, Nethra SS. Comparative study of two doses of intrathecal dexmedetomidine as adjuvant with low dose hyperbaric bupivacaine in ambulatory perianal surgeries: A prospective randomized controlled study. Indian J Anaesth. 


\section{5; 59:648-52.[Full Text] DOI}

9. Bromage PR. A comparison of the hydrochloride and carbon dioxide salts of lidocaine and prilocaine in epidural analgesia. Acta Anaesthesiol Scand (Suppl). 1965; 16:5569.[Full Text]

10. Ramsay MA, Savege TM, Simpson BR, Goodwin R. Controlled sedation with alphaxalone-alphadolone. Br Med J. 1974; 2:656-59.[Full Text]

11. Ishii H, Kohno T, Yamakura T, Ikoma M, Baba H. Action of dexmedetomidine on the substantia gelatinosa neurons of the rat spinal cord. Eur J Neurosci. 2008; 27(12):3182-90. [Full Text]

12. Eisenach JC, De Kock M, Klimscha W. Alpha sub 2-adrenergic agonists for regional anesthesia: A clinical review of clonidine (1984-1995). Anesthesiology. 1996; 85(3):655-74.

13. Al-Mustafa MM, Abu-Halaweh SA, Aloweidi AS, Murshidi MM, Ammari BA, Awwad ZM, et al. Effect of dexmedetomidine added to spinal bupivacaine for urological procedures. Saudi Med J. 2009; 30:365-70. [Full Text]

14. Gupta R, Bogra J, Verma R, Kohli M, Kushwaha JK, Kumar S. Dexmedetomidine as an intrathecal adjuvant for postoperative analgesia. Indian J Anaesth. 2011; 55(4):347-51.[Full Text]

15. Niu XY, Ding XB, Guo T, Chen MH, Fu SK, Li Q. Effects of intravenous and intrathecal dexmedetomidine in spinal anesthesia: A meta-analysis. CNS Neurosci Ther. 2013; 19:897-904. [Full Text]

16. Hutton P. Anesthesia for coloproctology. In: Keighly MRB, Williams NS, editors. Surgery of the Anus, Rectum and Colon, vol. 1. Philadelphia: WB Saunders company Ltd.; 1993. P 128-39.

17. Hocking G, Wildsmith JAW. Intrathecal drug spread. Br J Anaesth. 2004 Oct; 93(4):568-78.

18. Enk D, Prien T, Van Aken H, Mertes N, Meyer J, Brussel $\mathrm{T}$. Success rate of unilateral spinal anesthesia is dependent on injection flow. Reg Anesth Pain Med. 2001;26:420-27. [Science Direct]DOI

19. Horlocker TT, Wedel DJ. Density, specific gravity, and baricity of spinal anesthetic solutions at body temperature. Anesth Analg. 1993; 76(5):1015-18.[Full Text]

20. Tarkkila P, Huhtala J, Tuominen M. Home-readiness after spinal anaesthesia with small doses of hyperbaric $0.5 \%$ bupivacaine. Randomized controlled trial. Anaesthesia. 1997; 52(12):1157-60. [Full Text]

21. Wassef MR, Michaels EI, Rangel JM, Tsyrlin AT. Spinal perianal block: a prospective, randomized, double-blind comparison with spinal saddle block. Anesth Analg. 2007; 104:1594-6.[Full Text] 